NOTAS SOBRE AUTONOMIA E DESQUALIFICAÇÃO SOCIAL DE MULHERES PROSTITUTAS

NOTAS SOBRE LA AUTONOMÍA Y LA DESCALIFICACIÓN SOCIAL DE MUJERES PROSTITUTAS

NOTES ON AUTONOMY AND SOCIAL DISQUALIFICATION OF WOMEN PROSTITUTES

http://dx.doi.org/10.1590/1807-0310/2018v30165432

André Geraldo Ribeiro Diniz ${ }^{1}$ e Claudia Mayorga ${ }^{1}$

${ }^{1}$ Universidade Federal de Minas Gerais, Belo Horizonte/MG, Brasil

\begin{abstract}
RESUMO
Os discursos que concebem as prostitutas como vítimas são tensionados, por elas, pela recorrente afirmação de suas autonomias. A pesquisa aqui apresentada se deu a partir de imersão na Zona Boêmia da Rua Guaicurus, na cidade de Belo Horizonte, e de entrevistas com oito mulheres prostitutas. Apresentamos alguns mecanismos psicossociais que impedem o acesso das prostitutas ao circuito instituído de reconhecimento social, analisando a associação desses mecanismos com experiências de enfrentamento e resistência a dinâmicas de desqualificação social. As narrativas das prostitutas entrevistadas nos dão pistas de que suas trajetórias se constroem entre sujeição e resistência à sujeição, heteronomia e afirmação de autonomia. A ambiguidade das dinâmicas sociais lhes permite interpelar os efeitos destrutivos da subalternidade e, como efeito disso, elas disseminam no tecido social outros saberes sobre suas condições de vida.
\end{abstract}

Palavras-chave: prostituição; autonomia; resistência; gênero.

\title{
RESUMEN
}

Los discursos que conciben a las prostitutas como víctimas son tensados por ellas por la demandante afirmación de sus autonomías. La investigación aquí presentada se dio a partir de inmersión en la Zona Bohemia de la calle Guaicurus, en la ciudad de Belo Horizonte, y de entrevistas con ocho mujeres prostitutas. Presentamos algunos mecanismos psicosociales que impiden el acceso de las prostitutas al circuito instituido de reconocimiento social, analizando la asociación de esos mecanismos con experiencias de enfrentamiento y resistencia a dinámicas de descalificación social. Las narrativas de las prostitutas entrevistadas nos dan pistas de que sus trayectorias se construyen entre sujeción y resistencia a la sujeción, heteronomía y afirmación de autonomía. La ambigüedad de las dinámicas sociales les permite interpelar los efectos destructivos de la subalternidad y, como efecto, diseminan en el tejido social otros saberes sobre sus condiciones de vida.

Palabras clave: prostitución; autonomía; resistencia; género.

\begin{abstract}
The discourses that conceive prostitutes as victims are strained by them by the recurrent affirmation of their autonomies. The research presented here came from immersion in the Bohemian Zone of Guaicurus Street, in the city of Belo Horizonte, and from interviews with eight female prostitutes. We present some psychosocial mechanisms that prevent the access of prostitutes to the established circuit of social recognition, analyzing the association of these mechanisms with experiences of coping and resistance to dynamics of social disqualification. The narratives of the interviewed prostitutes give us clues that their trajectories are built between subjection and resistance to subjection, heteronomy and affirmation of autonomy. The ambiguity of social dynamics allows them to question the destructive effects of subalternity and, as a result, they disseminate in the social fabric other knowledge about their living conditions.
\end{abstract}

Keywords: prostitution; autonomie; resistance; gender. 


\section{A prostituição e a questão da autonomia}

$\mathrm{Na}$ atualidade, encontra-se uma significativa literatura que se debruça sobre a prostituição de mulheres. São trabalhos realizados, em sua maioria, no campo sociológico, antropológico, psicológico, médico/sanitarista e do direito. Desenvolvem-se a partir de uma pluralidade de categorias de análise como trabalho, classe social, sexualidade, gênero, migração, território, identidade, saúde, violência e juventude. Poucos são os estudos que abordam a categoria raça. Essa categoria é encontrada em associação com os estudos de processos migratórios, muitas vezes vinculado à categoria etnia.

Tais estudos, geralmente, são históricos (Engel, 1989; Fonseca, 1982; Roberts, 1998; Soares, 1992), descritivos/exploratórios (Barreto, 2008; Barros, 2002; Fábregaz-Martinez，2000; Guimarães，2007; Rodrigues, 2010; Viana, 2001) ou explicativos (Guimarães \& Merchán-Hamann, 2005; Jayme, Chacham, \& Morais, 2013; Mattos, 2009a; Rios, 2000; Rodrigues, 2003). No caso destes últimos, os estudos buscam analisar a prostituição tentando identificar causalidades ou gêneses nessa experiência.

As pesquisas e estudos feministas também possuem significativa contribuição na literatura acessada. Esse campo também é vasto e aborda a prostituição a partir de interesses distintos, em suas articulações com sexualidade, migração, trabalho, violência, direitos humanos e desigualdades de gênero (Fonseca, 1996; Garaizabal, 2001, 2006; Pateman, 1988/1993; Piscitelli, 2008, 2011; Rodrigues, 2009; Rubin, 1984/1989). No caso da psicologia, encontramos alguns estudos de abordagem clínica e do desenvolvimento (Douville, 2007; Marchiori, 2005), estudos com abordagem fenomenológica (Molina, 2003) e, em sua maioria, trabalhos em psicologia social, que também apresentam heterogeneidade teórico-metodológica (Barreto, 2008; Castro, 1993; Guimarães \& Merchán-Hamann, 2005; Lopes, Rabelo, \& Pimenta, 2007; Mayorga, 2009, 2011, 2012a, 2012b; Rodrigues, 2010; Viana, 2001).

Tais produções se fundamentam em um quadro teórico e conceitual heterogêneo e foi possível identificar que muitos desses trabalhos partem de uma análise "externa" dessa experiência, ou seja, não tomam a experiência das prostitutas como sujeitos de pesquisa. Os resultados e apontamentos de vários desses trabalhos apresentam uma realidade de extrema violência, segregação, desqualificação e inferiorização das mulheres prostitutas, reafirmando as representações negativas sobre elas e seu trabalho, além de subsidiar posições abolicionistas da prostituição em espaços de luta e ação política. Nos estudos psicossociológicos e articulados com o feminismo encontramos um quadro diferente, mas essa tensão está presente.

Se alguns desses estudos, por um lado, contribuem para evidenciar os processos de desqualificação social que circunscrevem a vida das prostitutas, por outro, mantêm as mulheres que protagonizam essa experiência em posições vitimizantes, destituindoas, portanto, de agência. Essas pesquisas dão luz aos sistemas de poder que influenciam ou determinam a entrada e manutenção dessas mulheres na prostituição sem, contudo, apresentar os sentidos e significados atribuídos por elas às suas próprias experiências. Há ainda aquelas que escutam as mulheres no processo de investigação, mas acabam por enquadrar suas narrativas em mapas teórico-conceituais predefinidos.

Ao nos aproximarmos dessa literatura, percebemos também a prevalência de duas tendências analíticas. Uma delas, geralmente sustentada na tradição estruturalista, lança luz aos aspectos estruturais que circunscrevem as pessoas e os grupos. Ela secundariza o indivíduo, ao compreendê-lo como efeito de um sistema, de uma estrutura e/ou de uma organização externa e anterior a ele. A agência, nesses estudos, é muitas vezes "desagenciada". Por vezes, eles lembram as análises sociológicas de Durkheim, em que a ação humana é efeito de determinantes externos ao indivíduo, localizados nas estruturas sociais. A segunda tendência investe atenção ao indivíduo, dando a ele centralidade no processo de pesquisa. Ao fazê-lo, relegam os determinantes estruturais da sociedade a um segundo plano e incorrem no risco de produzir a ideia de um sujeito autocentrado, capaz de definir sozinho seu percurso. Vemos essa tendência se materializar em estudos da psicologia clínica, em estudos cognitivistas ou em algumas perspectivas pósestruturalistas. Dentre as várias interpretações possíveis para essas tendências identificadas na literatura, não poderíamos deixar de trazer para o debate a clássica tensão que se faz pano de fundo nas ciências humanas e sociais. Cara à psicologia como campo, a dicotomia indivíduo $\mathrm{x}$ sociedade segue disseminando seus efeitos no processo de produção do conhecimento, (re) produzindo concepções de sociedades autorreguladas e/ou de indivíduos que se autodeterminam à revelia da sociedade.

A reflexão sobre a experiência da prostituição muitas vezes se dá reproduzindo essa dicotomia: ou são compreendidas como totalmente determinadas e efeitos de sistemas de opressão, ou são compreendidas a partir de uma autonomia absoluta. Em nossa perspectiva, faz-se necessário abordar essa experiência 
como uma perspectiva entre indivíduo e sociedade (Santos \& Mayorga, 2017).

As reflexões aqui apresentadas são parte de uma pesquisa desenvolvida na Universidade Federal de Minas Gerais, tendo como principal objetivo identificar e analisar experiências de enfrentamento e resistência à opressão (agenciamentos) na experiência de mulheres que exercem prostituição na região da Rua Guaicurus, em Belo Horizonte, MG. Para tanto, apresentaremos alguns mecanismos psicossociais identificados no estudo que impedem ou dificultam o acesso de mulheres prostitutas ao circuito instituído de reconhecimento social. Ao mesmo tempo, e sobretudo, analisaremos alguns efeitos intransparentes e inarticulados desses mecanismos no cotidiano dessas mulheres e sua associação constitutiva com experiências de enfrentamento e resistência a dinâmicas de desqualificação social. Numa perspectiva construcionista-interacionista, estas duas facetas (opressão e resistência) parecem estar presentes no cotidiano das mulheres por nós entrevistadas, mútua e paradoxalmente, de maneira constitutiva e indissociável.

As tendências vislumbradas em nossa análise refletem um importante dilema que constitui o debate atual sobre a prostituição. Esse dilema se equaciona, geralmente, em questões relacionadas ao grau de autonomia ou submissão que subjaz à entrada e permanência das mulheres prostitutas "na vida". Certamente, nossas reflexões também se localizam no centro desse dilema. Seguimos com o interesse em compreender processos de desigualdade, não somente pela elucidação de seus mecanismos de reprodução, mas, sobretudo, pela aproximação da experiência do(a) subalterno(a) e das formas de enfrentamento que são produzidas por ele(a). Nesse sentido, perguntamos: que agência é possível na experiência de mulheres prostitutas? Que enfrentamentos podem ser identificados em seus cotidianos? É possível identificar micropolíticas de resistência nessas experiências? Essas micropolíticas produzem efeitos em projetos emancipatórios coletivos mais amplos? Que potencial têm essas resistências e enfrentamentos de interferir na reprodução de desigualdades? Essas perguntas colocaram para este estudo um desafio fundamental: é preciso considerar a vivência das prostitutas e os sentidos e significados atribuídos por elas às suas próprias experiências; é fundamental nos aproximarmos das narrativas construídas pelas prostitutas sobre suas condições de vida e conhecer melhor seu cotidiano de batalha. Consideramos que há nessa experiência importantes potências para processos emancipatórios.
Foi importante considerar, em nossas análises, aqueles elementos normativos que circunscrevem a vida das prostitutas (Butler, 2010; Foucault, 1979/2010). Identificar posições de agência pressupõe identificar as forças de coerção que atuam em seu cotidiano. É a existência de tais forças que possibilita a emergência de enfrentamentos. Nesse sentido, buscamos construir um mapa teórico e conceitual capaz de, por um lado, ajudar-nos a compreender algumas dinâmicas estruturais de opressão e desqualificação que circunscrevem a prostituição, e, por outro, contribuir para a identificação de porosidades e descontinuidades dessas dinâmicas. Interessou-nos, portanto, localizar as interdições imputadas às mulheres prostitutas por sua condição de subalternidade mas, também, identificar possibilidades de agência dessas mulheres em suas trajetórias, através da análise de suas narrativas e dos espaços de sociabilidade que vivenciam.

\section{Sobre o método e o campo de pesquisa}

Buscamos contribuir com o debate, a partir de uma compreensão construcionista da realidade social, tomando uma posição interacionista sobre a prostituição. Acreditamos que essas posições teóricometodológicas podem ser frutíferas para a análise de experiências de agenciamentos em contextos de subalternidade, ao dar crédito à dinâmica que as produz e a sua natureza contraditória, ambígua e paradoxal. A constituição subjetiva e o exercício da autonomia prescindem da experiência intersubjetiva, já que consideramos que a socialização e individualização participam de um mesmo processo ontogenético (Mead, 1937/1968).

Com a radicalização da relação social como locus primeiro da realidade, buscamos construir uma interlocução com o campo de pesquisa e com alguns modelos teóricos explicativos, tomando por pressuposto uma epistemologia feminista "aplicada" ao campo da Psicologia Social, a partir da "análise da experiência" (Scott, 2001) e com um horizonte de objetividade enquanto "pesquisa situada" (Haraway, 1995).

O método utilizado foi de inspiração etnográfica. Foram realizadas observações participantes entre os meses de junho e dezembro de 2012, registradas em diário de campo, além de oito entrevistas semiestruturadas com mulheres que trabalham em hotéis da região da Rua Guaicurus, na cidade de Belo Horizonte.

Localizada no hipercentro da capital mineira, a região da Rua Guaicurus abriga inúmeros hotéis de 
prostituição onde as mulheres marcam seus "pontos" nos bancos e cantos da praça, em meio ao tumulto do centro e da intensa circulação de transeuntes. É uma região que congrega serviços, comércios e outras ofertas para as camadas populares da cidade, o que a torna uma região de circulação preponderantemente popular (Barreto, 2008). As características da região oportunizam o desenvolvimento de trabalhos informais como coleta de material reciclável, prostituição, arte popular de rua e comércio ambulante. A marginalização histórica desse espaço potencializa práticas ilícitas como o uso e tráfico de drogas, pequenos furtos, estelionato e exploração do trabalho infanto-juvenil, assim como agrega diferentes modos de vida marginais como a mendicância e a trajetória de vida nas ruas. A prostituição nos hotéis participa ativamente das interações da região boêmia da cidade.

Compondo o cenário dos corredores, veemse homens andando, parados, olhando para o tempo, conversando, passeando entre um quarto e outro. Há sempre música de fundo. Entre uma balada de funk, pagode ou dance music, escutam-se sempre os passos dos clientes pelos corredores, conjugados com gargalhadas e prosas. Em cada quarto, uma surpresa. Deitadas, de bruços, sentadas, dançando, assistindo TV, lixando as unhas, lendo revistas, discretas, despudoradas, brancas, loiras, pardas, gordas, negras, jovens, senhoris, cordiais, sedutoras, apáticas... prostitutas mil desfilam seus atrativos pelos corredores e pelos quartos. Segundo um levantamento realizado pela Associação das Prostitutas de Minas Gerais (APROSMIG) em 2011, há cerca de duas mil mulheres prostitutas na região boêmia.

É necessário justificar, ainda, nesta seção que trata do método e do campo, por que utilizamos a terminologia prostitutas, e não profissionais do sexo ou trabalhadoras do sexo. Inspirados no pensamento e luta da ativista Gabriela Leite (2009), estamos de acordo com sua reflexão sobre a necessidade de utilizar as palavras como são empregadas no cotidiano. Faz parte do processo de desestigmatização das mulheres que exercem a prostituição, segundo Leite, evitar eufemismos ou nomes higienizados acerca de sua ocupação.

\section{Prostituição e suas interdições psicossociais: algumas economias da desigualdade}

Compreendemos que uma leitura sobre a prostituição que considere o contexto social e histórico não poderia deixar de analisar um conjunto de condições sociopolíticas que, em nossa avaliação, nos ajudam a compreender a experiência da prostituição e sua emergência como sujeitos políticos no contemporâneo.

A primeira delas se refere à virada discursiva desencadeada nos séculos XIX e XX, denominada por Laclau e Moufee (1987) de "passagem das relações de subordinação para a consciência das relações de opressão" (p. 171). Na leitura de Prado (2002), essa passagem é possibilitada quando há uma consciência do agente social sobre a natureza impeditiva e privativa da dependência e da hierarquia. Nas relações de subordinação, esses impedimentos e privações são vistos como funcionais, produzindo uma reciprocidade intersubjetiva entre "inferior" e "superior". A consciência de opressão pressupõe a percepção de antagonismos nas relações de subordinação. Esse processo de conscientização é evidenciado, por exemplo, nas lutas políticas dos movimentos sindicais, feministas e negros. O que caracteriza essa passagem das relações de subordinação para as relações de opressão como uma virada discursiva da modernidade é sua ampla generalização na sociedade. Machismo, racismo, violência, homofobia, exploração, xenofobia e outros termos que tematizam relações antagônicas entre grupos sociais são, hoje, difundidos no tecido social.

A segunda condição de possibilidade, histórica e política, indissociável da primeira, se refere à emergência, no final do século XX, de lutas políticas protagonizadas por prostitutas, no Brasil e no mundo, especialmente após o surgimento do HIV/AIDS (Barreto, 2015). Os movimentos de mulheres prostitutas atualizam e fortalecem, com as especificidades dessa experiência, uma consciência coletiva da opressão que se estabelece em seus cotidianos. Muitas vezes, articulados a movimentos feministas e ao movimento LGBT, esses movimentos têm disseminado ideais e valores igualitários entre as prostitutas que, certamente, permitem a elas (re) significar suas experiências e, conforme pressupomos, fortalecer cotidianos de enfrentamento também ao nível das microrrelações.

Especificamente na região da Guaicurus, a APROSMIG tem vivenciado momentos conturbados para enfrentar as políticas higienistas orquestradas pelo poder público local. Com a criação do projeto de revitalização do centro da capital mineira, desde 2004, especialmente com o "Programa Centro Vivo", uma série de medidas têm sido tomadas para conter a atividade na região. Perseguições policiais no entorno da Rua Guaicurus, cassação de alvarás de funcionamento e fechamento de hotéis foram circunstâncias que levaram prostitutas, donos de hotéis, comerciantes e membros de ONGs a se organizarem 
politicamente (Barreto, 2008). Esse conflito local, que tem fortalecido a organização política das mulheres prostitutas da zona boêmia, constitui nossa terceira condição de possibilidade para a identificação de agenciamentos em suas experiências.

Refletindo acerca do pensamento da Butler (2010) que afirma que não existe possibilidade de agência fora da Norma, buscamos, na pesquisa aqui apresentada, considerar aqueles elementos normativos que circunscrevem a vida das prostitutas. Identificar posições de agência pressupõe identificar as forças de coerção que atuam em seu cotidiano. É a existência de tais forças que possibilita a emergência de enfrentamentos. A prostituição, na modernidade, configura-se como experiência subalternizada: a prostituta está impedida pelos dispositivos instituídos de saber/poder de se representar politicamente e de produzir e narrar sua própria história e sua própria percepção do mundo (Spivak, 1988/2010). Quase tudo que sabemos sobre elas não foi por elas narrado.

Identificamos inúmeros efeitos materiais e simbólicos do capitalismo nas dinâmicas de subalternização da prostituição da zona boêmia. Seguimos as premissas de Bourdieu (1995) ao pressupor que todas as sociedades mascaram suas relações de dominação, invisibilizando seus efeitos econômicos, já que o capitalismo transforma as relações sociais em capitais específicos, e a ilusão que naturaliza as desigualdades é inevitável. Assim, a partir de nossas observações em campo e suas respectivas análises, apresentamos elementos para a compreensão de algumas "economias da prostituição" (economias políticas), que nos possibilitaram remontar alguns discursos que operam no contexto da zona boêmia, assim como identificar as relações de acúmulo, apropriação e expropriação de poder e privilégio na desqualificação da prostituta: uma economia moral, uma economia emocional e uma economia sexual.

$\mathrm{O}$ que chamamos de economia moral nada mais é do que um sistema hierárquico prevalecente no ocidente moderno que obscurece os valores morais históricos que sustentam as ações e "escolhas" cotidianas. É um sistema de articulação das práticas cotidianas que torna opaca e intransparente a hierarquia moral valorativa que se produziu no ocidente moderno, em que serão reconhecidos como dignos apenas os indivíduos que operarem o seguinte esquema psicossocial: "ser plástico, moldável, flexível, disciplinado, autocontrolado, responsável por si próprio, orientado para o futuro e para o cálculo prospectivo" (Souza, 2003, p. 83). O que Taylor (1997) chama de self pontual. O trabalho "útil e produtivo" tem nesse sistema uma posição central e uma dimensão importante, que (des)qualifica a prostituta, cotidianamente, como indigna e imoral.

Identificamos também uma economia emocional que opera na subalternização da prostituta, e que se produz a partir dos mecanismos que materializam no cotidiano social e nos corpos o self pontual de Taylor. E conforme nos apresenta a teoria sociológica de Jessé Souza, o conceito de habitus de Bourdieu contribui para compreender de que forma determinados sistemas de valores se tornam "carne e osso" no cotidiano das putas pobres, mantendo intactas a ideologia espontânea do capitalismo e as lutas de classe e fração de classe. O habitus implica a apropriação de precondições econômicas e sociais que, traduzidas no sujeito como um conjunto de estruturas perceptivas e avaliativas, servem como uma espécie de filtro para quaisquer outras experiências posteriores (Bourdieu, 2006). O habitus materializa a estrutura, garantindolhe eficácia cotidiana através da corporificação de seus valores e inscrevendo nos organismos esquemas de percepção, pensamento e ação. As putas pobres, a partir de seus esquemas psicossociais adquiridos em contextos de socialização popular, são cotidianamente (des)classificadas.

Por fim, evidenciamos a presença de uma economia sexual da prostituição, que tem no sistema sexo/gênero sua principal tecnologia de produção e manutenção da desqualificação da prostituta. O sistema sexo/gênero "é o conjunto de disposições pela qual uma sociedade transforma a sexualidade biológica em produtos da atividade humana, e no qual se satisfazem essas necessidades humanas transformadas" (Rubin, 1989, p. 97, tradução nossa). No caso da prostituição de mulheres, esse sistema é desestabilizado. O uso do sexo para fins comerciais insere essa prática sexual em posições bem desfavoráveis no que Rubin (1989) denomina de "hierarquia dos atos sexuais", assim como a subversão de papéis e funções sociais atribuídos socialmente à mulher torna as prostitutas suscetíveis a intensos processos de desqualificação.

\section{Quando a puta afirma sua autonomia: idilio ou expressão de resistência?}

As mulheres prostitutas lidam cotidianamente com discursos sociais que tendem a fixá-las em posições de passividade diante da vida. Seja pelo discurso da doença, da demonização ou da vitimização social, as explicações e interpretações sobre sua condição de prostitutas, recorrentemente, associam suas vidas a um barco à deriva. 
Em meio a essa disputa de interpretações, na contramão dos discursos convencionais sobre "por que prostituir-se", vimos mulheres afirmando suas autonomias e seu poder de decisão, seja nas entrevistas individuais, seja nas conversas informais ou nos espaços políticos ocupados pela APROSMIG. Suas narrativas se associam, de alguma forma, a pronunciamentos como o de Morgane Merteuil, prostituta, feminista, engajada na organização política de trabalhadoras do sexo que reivindicam do Estado francês o reconhecimento jurídico da prostituição. "Sim, os homens podem ser amorosos e cuidadosos. $\mathrm{Sim}$, as mulheres podem amar o sexo. E sim, prostituirse pode ser uma forma de reapropriar-se do próprio corpo e da sexualidade (tradução nossa)"'.

Das oito entrevistadas deste estudo, pelo menos quatro se inseriram na prostituição a partir de situações que envolveram violência e opressão de gênero. Essas situações são explícitas em suas histórias, apesar de, não raro, elas construírem narrativas extremamente autorreferidas e autodeterminadas sobre si e afirmarem veementemente suas autonomias na escolha da prostituição. A presidente da APROSMIG, em seus pronunciamentos públicos, recusa recorrentemente o rótulo de vítima às mulheres prostitutas. Ela sempre reafirma a seus interlocutores que a prostituição é, para ela e para outras prostitutas, uma escolha, uma experiência de autonomia. Será idílio? Será penas "transformação de necessidade em virtude"??

Jéssica ${ }^{3}$, após o término de um relacionamento, foi ameaçada de morte pelo ex-namorado. Teve que sair de sua cidade em busca de proteção. Divorciada do marido, Patrícia se deu conta de que não conseguiria manter o padrão de vida de seus filhos nas condições em que se encontrava. Laura, após o nascimento da filha, fruto de uma relação "extraoficial", foi expulsa de casa e se viu impelida a encontrar um meio de vida para sustentá-las.

Diante dessas situações, elas constroem uma narrativa para a inserção ou permanência na prostituição, configurando-se em "avaliações fortes". $\mathrm{Na}$ perspectiva de agência humana do filósofo canadense Charles Taylor, há uma distinção entre as avaliações que fazemos de nossas escolhas no cotidiano: as avaliações fortes e as avaliações fracas. A diferença básica entre elas é que nas avaliações fracas o julgamento dos desejos se baseia na tentativa de identificação de qual das alternativas acessíveis é a mais adequada - "isso" ou "aquilo?". Já as avaliações fortes pressupõem uma avaliação qualitativa do conteúdo dos desejos, já que as motivações do desejo são colocadas em juízo - desejar "isso" é bom? / desejar "aquilo" é virtuoso? (Taylor, 1977/2007).
O tema das avaliações fortes atribui maior ênfase às noções de bem ou mal que estão por detrás dos julgamentos humanos. Como elas são realizadas a partir de avaliações por contrastes - bom/ruim, desejável/não desejável, virtuoso/não virtuoso, feio/ bonito, agradável/desagradável -, marcam um pano de fundo moral da agência humana. Elas avaliam a virtuosidade em se escolher essa ou aquela alternativa. O que está em jogo no julgamento de nossas ações é o quão desejáveis devem ser nossos desejos. Em outras palavras, nossos julgamentos atendem à necessidade constante de responder à pergunta moral: "que vida vale a pena ser vivida?" (Taylor, 1997, 1977/2007).

"Preferi fazer vida do que aguentar as humilhações da minha mãe”. (Laura, 56 anos, hotel Nova América, 29/11/2012)

"vou sair daqui pra fazer o quê? Empregada doméstica? Não, não dá não... Isso eu já era lá em casa sem um tostão. Prefiro continuar aqui". (Capitu, 41 anos, hotel Magnífico, 15/11/2012) "Não quis depender dele [do ex-marido]. Isso do
conforto. E você não deixar seus filhos estudar na
escola pública. Nada contra.. Tem mais qualidade
de vida. Tive que encontrar uma forma de ganhar
dinheiro, porque era isso ou ter que ficar pedindo
dinheiro pra ex-marido". (Gabriela, 33 anos, hotel
Onda Livre, 08/11/2012)

"Se pra não ter que depender de homem eu tiver que morrer prostituta, que seja. O mundo mudou." (Jéssica, 32 anos, hotel Jardim América, 19/11/2012)

Por esses relatos, fica evidente que as mulheres entrevistadas se encontravam em condições econômicas e sociais precárias. É, também, por força dessas condições que a prostituição surge no escasso hall de alternativas que essas mulheres vislumbram, o que certamente levou Mattos (2009) a perceber, em seu estudo, que a prostituição é uma atividade comum entre as mulheres da "ralé brasileira" (Souza, 2003). Atrelada às aparentes "avaliações fracas" que fazem pano de fundo para a tomada de decisão das entrevistadas, vemos uma avaliação contrastiva que transversaliza a narrativa de várias delas. "Prostituir-se ou submeter-se a um homem?"; "Prostituir-se ou ser humilhada?"; "Prostituir-se ou ser empregada doméstica?"; "Prostituir-se ou depender do ex-marido?". Essas são algumas das tensões que se puseram diante das participantes. Certamente, as dinâmicas que envolvem a entrada e permanência das mulheres na prostituição são bem mais complexas do que uma simples escolha entre "isso ou aquilo". Essa é apenas uma estratégia analítica que acreditamos ser frutífera para demonstrar a existência de panos de 
fundo morais em suas trajetórias - de caráter produtivo, e não somente coercitivo.

Essas avaliações podem ser interpretadas, em termos de princípios morais, como uma tensão entre "autonomia" e "heteronomia". Essa tensão confere às dinâmicas de reconhecimento diferencial da prostituição um caráter contraditório, pelo qual sua desqualificação tem por horizonte a heteronomia, enquanto que o enfrentamento à desqualificação busca afirmar sua autonomia. Conforme percebemos nas narrativas de Jéssica, Gabriela, Laura e Capitu, a forma como as alternativas lhes foram apresentadas demonstra suas condições de subalternidade. Contudo, mesmo diante de alternativas limitadas, a avaliação das possibilidades que lhes são apresentadas pressupõe um horizonte moral. No contexto da tomada de decisão, a prostituição se apresenta a essas mulheres como possibilidade de aproximação de uma experiência autônoma.

Seguindo o pensamento de Marcela Lagarde, feminista mexicana, a autonomia deve ser analisada num processo histórico a partir das condições em que cada grupo social se inscreve. Ela está inscrita simbolicamente na linguagem, na cultura, na estética, na sexualidade, na política, na filosofia, etc. A autonomia enquanto pacto social (Lagarde, 1997) necessita de uma rede de inteligibilidade que a reconheça, a legitime. Ela necessita de condições sociais concretas para ser exercida. Não se reduz apenas numa enunciação, ou numa proclamação, mas "o simples enunciado da necessidade da autonomia já é um princípio de autonomia simbolicamente falando" (p. 6, tradução nossa). Nesse sentido, a afirmação da autonomia, em seu sentido mais simples, já indica uma autonomia simbólica dos sujeitos.

A afirmação de autonomia na experiência da prostituição é, antes de tudo, um conflito de poderes que demonstra a não reciprocidade simbólica entre a força de desqualificação e a prostituta. Isso não implica a neutralização das sanções previstas para a insubmissão. Contudo, ainda que conheçam bem os caminhos de desqualificação que irão trilhar, essas mulheres parecem ter se inserido nessa atividade como uma possibilidade de terem vidas mais autogeridas. No caso de Gabriela, por exemplo, as condições de subalternização em um sistema sexo/gênero puseram-na em uma condição precária de escolha entre prostituir-se ou depender economicamente do ex-marido. Contudo, sua inserção nesse trabalho também envolveu uma afirmação de sua autonomia (econômica e sexual). Gabriela parece identificar maiores possibilidades de alcançá-la na prostituição do que numa condição de dependência econômica, ainda que tal decisão não parece ter sido sustentada numa reflexão organizada, do tipo "serei prostituta porque poderei ser autônoma e independente".

Por fim, temos indícios de que os caminhos trilhados por algumas prostitutas em função das interdições imputadas pelo sistema sexo/gênero, ambiguamente, sofrem influência de outro sistema de saber/poder: a busca pela autonomia. A "transformação de necessidade em virtude" pode ser entendida, a partir dessas análises, como efeito de resistência às normas do sistema sexo/gênero. Elas parecem recusar posições impostas, apostando na prostituição como uma possibilidade de se fazerem mulheres menos dependentes e mais realizadas.

\section{Afirma(ação) de autonomia não é idílio: é agir sobre si mesma e sobre o mundo}

O pressuposto da existência de experiências de enfrentamento à opressão e à desqualificação social da prostituta traz consigo o pressuposto da resistência. Mas de que forma a afirmação de autonomia pode ser compreendida como resistência? Para tentar responder a essa questão, apresento um fragmento do diário de campo da pesquisa que relata minha aproximação com Madalena.

Já eram nove da noite, observei uma garota num quarto isolado, no fundo do corredor, loira, bonita, com o perfil estético do hotel Brilhante. Quando me aproximei, fui logo informando meu nome e quem eu era. Perguntei-lhe se teria um ou dois minutos para apresentar-lhe a proposta da pesquisa. Antes mesmo de terminar, ela deu um longo sorriso e convidoume para entrar: "Senta aí gato, não repara não, tá." Enquanto sentava na cama, ela se levantou, acendeu a luz, retirou o fone de ouvido e estendeu na cama, à minha frente, uma camiseta lilás. Sorrindo para mim, Madalena me informou que foi ela própria quem a fez, apontando para os detalhes artesanais nas costuras laterais da camiseta. Mas o que me chamou mesmo a atenção foi a frase estampada na camisa: "Mulheres são iguais, em qualquer profissão". Como pano de fundo da frase, a silhueta de uma mulher, bastante sensualizada, parecendo estar observando o leitor. Porque ela teria me mostrado aquela camisa, tão logo entrei em seu quarto? (Diário de campo, Rua Guaicurus, 22/10/12, 18h)

Os vinteminutos de conversa do primeiro encontro com Madalena foram marcados por intensas investidas sexuais, sem interesses monetários. Constrangido e com poucas reações, tentei direcionar sempre a conversa para meu objetivo principal naquele encontro. Confesso que, até aquele dia, toda a aproximação do campo investiu-me de certo pessimismo em relação aos 
meus objetivos de pesquisa. Como poderia identificar agenciamentos numa experiência tão marcada pela instrumentalização, por relações estruturalmente econômicas, pela precariedade material e simbólica que se colocava diante de mim nas observações?

Agendamos a entrevista para o dia seguinte. Sua entrevista foi marcada por uma extrema autoconfiança. Contou sua história sem fraquejar. Parecia esbanjar felicidade com a vida que levava. Em episódios dramáticos, Madalena punha-se em postura firme e decidida. Mesmo com certa tristeza estampada no rosto, não parecia se ver como vítima de uma vida algoz. O sexo estava presente em parte significativa de sua narrativa. Quando solicitada a falar um pouco sobre o que significava para ela a felicidade, Madalena não hesitou em responder: "Sexo... Adoro!".

Várias das interpretações construídas a partir das narrativas de Madalena ao longo da entrevista estavam alicerçadas menos em meus referenciais teóricos do que em minhas predisposições psicossociais de homem branco, que compartilha alguns valores de classe média e que ocupa um lugar simbolicamente racionalizado (o da ciência). Certamente, eu não me despi delas ao adentrar no setting de entrevista. Ao contrário, elas pareceram obscurecer muitos dos elementos teóricos que, ao longo da construção de nosso referencial, sustentaram a hipótese de uma experiência que não se estruturava somente pela precariedade.

Enquanto pesquisador, importa meu sexo, minha identidade sexual e de gênero, minha raça, minha posição de classe. Quando Fonseca (1996) faz uma distinção entre pesquisas com prostitutas realizadas por homens e por mulheres, busca retratar as diferenças que se expressam no cotidiano de uma pesquisa, tal qual se expressaram em minhas interações com Madalena. Ela postula que há maior probabilidade de mulheres pesquisadoras abordarem as mulheres prostitutas como sujeitos autônomos do que homens pesquisadores. Nos estudos que ela analisou, a autonomia das mulheres, quando aparece, está sempre em segundo plano, associada a figuras masculinas. Minha experiência demonstrou que a hipótese de Fonseca (1996) não pode ser descartada. As posições, pensamentos e interpretações imediatas da experiência que me foi narrada têm mais relação com o caráter situado da produção de conhecimento (Haraway, 1995) e com a natureza sociológica da ciência do que com uma inabilidade metodológica.

Por "ironia do destino", a primeira das seis entrevistadas apresentou-se como uma mulher totalmente autorreferida, independente e feliz. Contudo, é possível identificar uma série de interdições com as quais ela se deparou. Interdições que, claramente, caracterizam sua experiência como uma experiência subalternizada: uma visível ausência da proteção familiar, o abandono e rejeição dos pais diante de sua decisão em assumir um namoro com um narcotraficante carioca e fugir com ele para o Rio de Janeiro (o que pode ser interpretado como omissão de socorro, caso as circunstâncias da fuga tenham envolvido coação ou assédio), o estupro sofrido no trabalho, as constantes agressões que vivenciou em suas relações afetivas, a forte dependência química que experimentou durante alguns anos de sua juventude. É difícil não interpretar a narrativa autodeterminada de uma vida marcada por atropelos, precocidades e precariedades afetivas e simbólicas como um idílio - ou como preferiria Pierre Bourdieu, como "necessidade transformada em virtude". Foi imediatamente o que fiz, ao final da entrevista.

Mas há um elemento fundamental da história de Madalena que nos saltou aos olhos: sua trajetória lhe permitiu experimentar o sexo e a sexualidade de formas bem diferentes das mais convencionais para uma mulher. Quando decidiu fazer o primeiro programa, sugestionada pelo namorado carioca, sentiuse insegura, receosa. Mas ao término do programa, a sensação era outra: "Nunca tinha ganhado aquele tanto de dinheiro só para fazer aquilo que eu gostava (gargalhadas). Falei por que eu não fazia isso antes? Estava rica agora" (Entrevista com Madalena, 19 anos, hotel Onda Livre, 23/10/2012).

Madalena sempre descreve os episódios de sexo que vivenciou, seja em programas, seja em relações afetivas, como prazerosos e agradáveis. Ela afirma ter feito "descontos" no pagamento de clientes quando esses the interessavam sexual ou afetivamente. Quando perguntada se atualmente sentia prazer com seus clientes, respondeu da seguinte forma: "É lógico. Sempre vem aquele menino novinho, gostoso. Aí, fico louca, vem aqui, vem, vou te dar desconto, vem, vem cá, vem cá, vem cá (risos), vem cá, gostoso".

O que fica evidente na história de Madalena é a possibilidade que a prostituição lhe deu de construir uma carreira sexual. A junção de sexo e dinheiro, como meios para conquistar outros recursos materiais e simbólicos, apresenta-se a ela como um perfeito casamento para alcançar suas expectativas da vida. As afirmações de Madalena evidenciam a existência de prostitutas que fazem da prostituição uma carreira sexual. Se essa é a vida que "vale a pena ser vivida" para Madalena, não será sem restrições. Rubin (1989) já nos mostrou as penalidades que a sociedade imputa às mulheres que ousam ultrapassar as barreiras da sexualidade reprodutora, marital e não comercial. Mas dessa forma ela vai levando a vida...de cidade 
em cidade... de "boleia de caminhão" em "boleia de caminhão".

Mas que efeitos concretos essa constante afirmação da autonomia produz? Por si só, ela representa mera artimanha do poder ou a evidência das lutas simbólicas por recursos escassos. Mas inscrita em contingências específicas, ela pode alcançar cadeias de inteligibilidade que a potencializam, produzindo novos e sucessivos efeitos. Remontar a história de Madalena é importante para nossas análises porque nos ajuda a demonstrar que sua narrativa autorreferida e autodeterminada produziu efeitos significativos nesta pesquisa. Não pretendemos aqui analisar os saberes que foram construídos nessas narrativas em termos de verdade/inverdade mas, sobretudo, identificar seus efeitos em nossa interação.

$\mathrm{Na}$ contingência de nosso encontro, sua autoestima e a afirmação constante de autonomia diante dos episódios que vivenciou desestabilizaram profundamente os rumos que este estudo tomava. A ambiguidade que caracterizava minha posição nessa contingência estava refletida, por um lado, nos valores, princípios, hierarquias e predisposições morais que se faziam representados pela minha presença (que, conforme demonstrado pelo fragmento do diário de campo, apresentavam fortes tendências a subestimar as possibilidades de agência das prostitutas) e, por outro, pela posição ético-política que venho tentando construir. De um lado, meu corpo material e simbólico, com todos os seus efeitos de poder, e, do outro, uma disposição à reflexividade, na busca por construir uma posição feminista no encontro com a experiência da prostituição - posição essa que tem na pressuposição da autonomia das mulheres um de seus principais pilares.

A narrativa de Madalena produziu efeitos intersubjetivos em nosso encontro. A desestabilização dos efeitos de poder desencadeados pelos discursos que se reproduziram através de mim no setting da entrevista foi imediata. Tal desestabilização se deu em função da disparidade entre as verdades que sustentavam algumas de minhas interpretações e os saberes que foram articulados pela narrativa de Madalena. O mais significativo desses efeitos foi a interpelação constante que essa narrativa proporcionou ao processo de reorganização do marco teórico da pesquisa, às entrevistas realizadas posteriormente e ao processo de análise dos dados.

Nossa interpretação só faz sentido a partir do pressuposto fundamental deste estudo, que atribui à relação social o locus primeiro da agência humana. A relação de pesquisa é uma relação social. A produção científica é de natureza sociológica. Se inscreve nas tramas do poder. É carregada de historicidade e, sobretudo, se sustenta numa experiência específica (Brah, 2006). Enquanto interação social, a relação pesquisador/pesquisada que foi estabelecida entre mim e Madalena parece ter criado condições para que uma suposta "transformação de necessidade em virtude" articulada em suas narrativas produzisse outros efeitos que não os de subalternização. Dessa perspectiva, "transformar necessidade em virtude", em interação contingencial, pode desestabilizar determinadas disposições estruturais da dominação: pode ter efeitos de agência. $\mathrm{O}$ que escrevemos neste texto é parte de nós e também parte delas. Algumas de suas percepções do mundo e da própria condição estão aqui inscritas, ainda que precariamente.

É importante correlacionar aqui, a partir das análises realizadas anteriormente, autonomia e resistência. Resistir é negar a legitimidade da norma, é interpelar a submissão à regra externa; é, sobretudo, desnudar a arbitrariedade da dominação. Nesse sentido, a microrresistência, investida de poder, se sustenta em outras normas, diferentes das dominantes. Ela emerge como efeito do poder de outros princípios que buscam se tornar imperativos. Isso nos permite perceber que a afirmação da autonomia não é simplesmente um idílio. Quando uma prostituta afirma sua autonomia diante de um ataque desqualificador ou de um discurso vitimizante, ela está, dentre outras coisas, afirmando uma não reciprocidade com o princípio que a desqualifica. Afirmar a autonomia é, em princípio, expressão de resistência. Ainda que não inscrita em mecanismos sociais de inteligibilidade, é expressão de lutas simbólicas (Bourdieu, 2006) que se instalam no interior do tecido social. Conforme propõe Lagarde (1997), a resistência, de um ponto de vista das teorias de gênero, inaugura a autonomia.

Contudo, ter produzido efeitos nesta pesquisa também não garante nenhum movimento maior de desestabilização da ordem dominante. Mas, se pensarmos nas pesquisas de Barreto (2008) e Fonseca (1996), na trajetória pessoal e política de Gabriela Leite e Cida Vieira, nos movimentos de mulheres prostitutas mundo afora, nas teorias feministas críticas e em outras experiências sociais que desafiam as prescrições do que deve ser uma mulher na sociedade, a história de Madalena passa a ter outro sentido. Parece haver um fio condutor que conecta essas experiências sociais: sua natureza política. Numa compreensão da autonomia como produção intersubjetiva,

as possibilidades de mudança social nascem do embate dialético entre o dado pela sociedade e o vir a ser pelo indivíduo. Entre o instituído e a ação do indivíduo há a presença de um self a mediar a relação, o que faz com que o dado e o vir a ser nunca coincidam totalmente. (Sant'Ana, 2009, p. 474) 
Associadas, uma experiência compartilhada, uma solidariedade estabelecida ou uma posição construída no exercício da reflexividade têm o potencial de transformar microrresistências em ações coletivas de reivindicação por equidade e justiça social.

\section{Considerações finais}

A aproximação com as experiências da prostituição na região da Guaicurus, na cidade de Belo Horizonte, mostrou o quão complexa é essa realidade. Carregados de ambiguidades e contradições, os contextos de vida das prostitutas entrevistadas demonstram que suas experiências são marcadas por intensas dinâmicas de subalternização.

Foi possível identificar ao longo do estudo uma série de dispositivos e mecanismos que se articulam na vida dessas mulheres, produzindo interdições morais, econômicas, simbólicas, emocionais e subjetivas em seus cotidianos. Um deles, o sistema sexo/gênero, parece restringir as possibilidades dessas mulheres se constituírem, material e subjetivamente, sem a convivência próxima com experiências de desqualificação e violência. Certamente, isso já era por nós esperado. Tamanha é a negatividade que a modernidade logrou conferir a essa experiência social que seria difícil um pesquisador se inserir neste campo sem pressupor a existência de cotidianos múltiplos de subalternização. Ao identificarmos dispositivos de subalternização no cotidiano da zona boêmia, contamos mais uma vez a versão de uma história que várias outras pesquisas já nos contaram sobre as prostitutas. História essa que, conforme alguns dados nos demonstraram, está impregnada em nossas instituições, em nossas predisposições de ação e percepção, em nossas organizações políticas e em nossas produções científicas: a história da puta que "não é", que "não pode", que "não deve" e que "não tem".

No entanto, a interação com as mulheres nos indica a existência de outras histórias que estão sendo criadas, compartilhadas e vividas por mulheres prostitutas. Madalena tem uma história para contar que é desconhecida da maioria das pessoas. Ela nos mostrou que somente parte dessa história é contada pelos "legítimos contadores de histórias". Gabriela contou que, por dezesseis horas diárias, ela não é como a personagem que os livros insistem em descrever. A "Gabriela puta" volta todos os dias para casa com um bom dinheiro conquistado no trabalho. Paga a mensalidade da escola dos filhos, ajuda-os no "dever de casa" e sonha com eles a decoração da casa que está para chegar.
Laura também nos contou histórias não contadas. A senhora de 56 anos, mãe de filha universitária, distinta, respeitosa, sai de casa todos os dias para conquistar seu salário mensal na zona boêmia da cidade. Não se contentando, ela ainda tem tempo para passar algumas horas diárias na associação que representa sua "classe", pensando formas de contar outras histórias, de si e de suas companheiras, diferentes daquelas que todos já conhecem.

As interdições psicossociais que circunscrevem o cotidiano das prostitutas da zona boêmia da Guaicurus parecem ter efeito de encobrir histórias. Mais do que isso, de contar uma história única sobre quem elas são e sobre como elas vivem. Spivak (2010) já nos demonstrou que essa é uma característica fundamental da subalternidade: é alijada do(a) subalterno(a) a possibilidade de contar suas próprias histórias.

E as histórias que elas nos contaram neste estudo não são somente histórias de sujeição, de vitimização ou de violência. As mulheres com quem dialogamos neste estudo permitiram-nos identificar algumas formas pelas quais as prostitutas têm afirmado suas autonomias. O trabalho rentável da prostituição permite a Gabriela seguir sua vida sem depender do ex-marido. Capitu parece ter encontrado na prostituição, ainda que a duras penas, uma alternativa à vida pacata que lhe destinaram no interior de Minas. Fadada a servir seus familiares em troca de migalhas, ela viu no conselho que recebeu de uma amiga uma forma de servir-se a si mesma. Ainda que, para isso, ela tivesse que sair do circuito instituído do reconhecimento social.

As narrativas das prostitutas entrevistadas nos dão pistas de que suas trajetórias se constroem entre sujeição e resistência à sujeição, heteronomia e afirmação de autonomia. A ambiguidade das dinâmicas sociais lhes permite interpelar os efeitos destrutivos da subalternidade e, como efeito disso, elas disseminam no tecido social outros saberes sobre suas condições de vida.

O pano de fundo moral que parece articular os enfrentamentos sustentados por elas demonstra que o contrapoder investido nesses enfrentamentos é, em alguma medida, compartilhado socialmente. O que nos leva a deduzir que a resistência é expressão de uma inscrição no poder, mas, sobretudo, na história e na cultura. Quando afirmam a autonomia, elas reavivam ideias, valores e princípios que buscam lograr-se como verdades na sociedade.

O maior empecilho que as prostitutas parecem enfrentar para desconstruir as verdades sobre sua condição de submissas são os efeitos de interdição produzidos pelas dinâmicas identitárias 
que as envolvem. Esses efeitos, que dificultam o estabelecimento de laços de solidariedade entre elas, fragilizam suas capacidades de acessar os circuitos da política para legitimar seus saberes e suas histórias.

\section{Notas}

1 Trecho retirado do panfleto "Liberad el Feminismo" publicado em 06 de setembro de 2012, por Morgane Merteuil, Secretária Geral do Sindicato das Trabalhadoras do Sexo - STRASS e citado pelo periódico El País, na coluna de Miguel Mora, em 05 de setembro de 2012. Recuperado em 15 de dezembro de 2015 de http://blogs. elpais.com/aqui-paris/2012/09/mejor-puta-que-trabajar-enuna-f\% $\mathrm{C} 3 \% \mathrm{~A} 1$ brica.html

2 Interpretação de Mattos (2009), consonante com o pensamento de Pierre Bourdieu, para os discursos autorreferidos, autodeterminados e supostamente idílicos das prostitutas entrevistadas em seu estudo.

3 Os nomes utilizados ao longo do texto são fictícios, com exceção de Laura, que reivindicou a manutenção de seu nome em função de sua atuação política na APROSMIG. Para as demais, utilizaremos os nomes Madalena, Bruna, Gabriela, Capitu e Jéssica.

\section{Referências}

Barreto, L. C. (2008). Prostituição, gênero e sexualidade: hierarquias sociais e enfrentamentos no contexto de Belo Horizonte. Dissertação de Mestrado, Faculdade de Filosofia e Ciências Humanas, Universidade Federal de Minas Gerais, Belo Horizonte, MG.

Barreto, L. C. (2015). Somos sujeitas políticas de nossa própria história? Prostituição e feminismos em Belo Horizonte. Tese de Doutorado, Programa de Pós-graduação em Interdisciplinar em Ciências Humanas, Universidade Federal de Santa Catarina, Florianópolis, SC.

Barros, L. A. (2005). Mariposas que trabalham: uma etnografia da prostituição feminina na região central de Belo Horizonte. Jus Navingandi (Teresina), 9(827), 1-3. Recuperado de http://www.egov.ufsc.br/portal/sites/default/files/ anexos/23531-23533-1-PB.pdf

Bourdieu, P. (2005). A economia das trocas simbólicas (6 $6^{\mathrm{a}}$ ed.). São Paulo: Perspectiva.

Bourdieu, P. (2006). A distinção: crítica social do julgamento (D. Kern \& G. Teixeira, trad., 2 ${ }^{\mathrm{a}}$ ed.). Porto Alegre: Zouk. (Trabalho original publicado em 1979).

Brah, A. (2006). Diferença, diversidade e diferenciação. Cadernos Pagu, 26, 329-376.

Butler, J. (2010). Deshacer el género (P. S. Beltran, trad.). Barcelona: Paidós.

Castro, R. V. (1993). Representações sociais da prostituição na cidade do Rio de Janeiro. In M. J. Spink (Org.), $O$ conhecimento no cotidiano: as representações sociais na perspectiva da psicologia social (pp. 149-187). São Paulo: Braziliense.

Douville, O. (2007). A jovem prostituta e sua mãe (P. Abreu, trad.). Tempo Psicanalítico, 39, 51-61.

Engel, M. (1989). Meretrizes e doutores: saber médico e prostituição no Rio de Janeiro (1840-1890). São Paulo: Brasiliense.
Fábregas-Martinez, A. I. (2000). Traçando a batalha: breve perfil da prostituição em espaços privados de Porto Alegre. In A. I. Fábregaz-Martinez \& M. R. Benedetti (Orgs.), $\mathrm{Na}$ batalha: identidade, sexualidade e poder no universo da prostituição (pp. 15-30). Porto Alegre: Dacasa; Palmarica.

Fonseca, G. (1982). História da prostituição em São Paulo. São Paulo: Resenha Universitária.

Fonseca, C. (1996). A dupla carreira da mulher prostituta. Estudos Feministas, 4(1), 7-34.

Foucault, M. (2010). Microfisica do poder $\left(28^{\mathrm{a}} \mathrm{ed}\right.$.). Rio de Janeiro. Edições Graal. (Trabalho original publicado em 1979)

Garaizabal, C. (2001). Una mirada feminista a la prostitución. In Jornadas Feministas: Feminismo.es... y será: ponencias, mesas redondas y exposiciones (pp. 33-42). Espanha: Universidad de Córdoba, Servicio de Publicaciones. Recuperado de http://dialnet.unirioja.es/servlet/ $\underline{\text { libro? } \operatorname{codig} 0}=2218$

Garaizabal, C. (2006). Por los derechos de las trabajadoras del sexo. Viento Sur, 87, 62-72. Recuperado de http://vientosur. info/articulosabiertos/vs_0087.pdf

Guimarães, R. M. (2007). Prostituição: patologia, trabalho, prazer? $O$ discurso de mulheres prostitutas. Dissertação de Mestrado, Programa de Pós-graduação em Filosofia, Ciências e Letras, Departamento de Psicologia e Educação, Universidade de São Paulo, Ribeirão Preto, SP.

Guimarães, K. \& Merchán-Hamann, E. (2005). Comercializando fantasias: a representação social da prostituição, dilemas da profissão e a construção da cidadania. Estudos Feministas, 13(3), 525-544

Haraway, D. (1995). Saberes localizados: a questão da ciência para o feminismo e o privilégio da perspectiva parcial. Cadernos Pagu, 5, 07-41.

Jayme, J. G., Chacham, A. S., \& Morais, M. R. (2013). Mulheres da "Zona Grande": Negociando identidade, trabalho e território. Sexualidad, Salud y Sociedad Revista Latinoamericana, 14,138-163.

Laclau, E. \& Moufee, C. (1987). Hegemonía y estrategia socialista. Buenos Aires: Fondo de Cultura Económica.

Lagarde, M. (1997). Claves feministas para el poderío y la autonomía de las mujeres. Managua: Puentos de Encuentro.

Leite, G. (2009). Filha, mãe, avó e puta: a história de uma mulher que decidiu ser prostituta. Rio de Janeiro: Objetiva.

Lopes, C. S., Rabelo, I. V. M., \& Pimenta, R. P. B. (2007). A bela adormecida: estudo com profissionais do sexo que atendem à classe média alta e alta na cidade de Goiânia. Psicologia \& Sociedade, 19(1), 69-76. Recuperado de http://www.scielo. br/pdf/psoc/v19n1/a10v19n1.pdf

Marchiori, H. (2005). La personalidad de la mujer delincuente. In Personalidad del delincuente (6 ${ }^{\mathrm{a}}$ ed., pp. 191-205). México: Porrúa. Recuperado de http://biblio.juridicas. unam.mx/libros/2/689/11.pdf

Mattos, P. C. (2009a). A dor e o estigma da puta pobre. In J. Souza et al. (Orgs.), A ralé brasileira: quem é e como vive (pp. 173-204). Belo Horizonte: Editora UFMG.

Mattos, P. C. (2009b). Os efeitos sobre o reconhecimento: um estudo empírico sobre prostituição. In K. B. Oliveira \& G. G. Oliveira (Orgs.), Olhares sobre a prevenção à criminalidade (pp. 81-98). Belo Horizonte: Instituto Elo.

Mayorga, C. (2009). El tráfico de mujeres como problema: colonialismo y patriarcado. Revista Electrónica de Psicología Política, 7(21), p. 74-102.

Mayorga, C. (2011) Cruzando fronteiras: prostituição e imigração. Cadernos Pagu, 37, 28-60. 
Mayorga, C. (2012a). Notas feministas sobre o marco jurídico da migração e do tráfico de mulheres na Europa e Espanha. INTERthesis, 9(1), 278-304.

Mayorga, C. (2012b). Articulaciones de la exclusión: la política de atención a prostitutas inmigrantes en Madrid. Si Somos Americanos, 12(1), 48-74.

Mead, G. H. (1968). Espíritu, persona y sociedad: desde el punto de vista del conductismo social. Paidós: Buenos Aires. (Trabalho original publicado em 1934).

Molina, A. M. R. (2003). Prostituição Juvenil: uma condição existencial em busca de seus sentidos. Psicologia, Ciência e Profissão, 23(2), 22-29.

Pateman, C. (1993). O contrato sexual (M. Avancini, trad.). Rio de Janeiro: Paz e Terra.

Piscitelli, A. (2008). Interseccionalidades, categorias de articulação e experiências de migrantes brasileiras. Sociedade e Cultura, 11(2), 263-274.

Piscitelli, A. (2011). Migração e sexualidade: do Brasil à Europa. In S. Corrêa \& R. Parker (Orgs.), Sexualidade e Política na América Latina: histórias, interseções e paradoxos (pp. 247-258). Rio de Janeiro: ABIA. Recuperado de http://www. sxpolitics.org/pt/wp-content/uploads/2011/07/dialogo- la total final.pdf

Prado, M. A. M. (2002). Da mobilidade social à constituição da identidade política: reflexões em torno dos aspectos psicossociais das ações coletivas. Psicologia em Revista, $8(11), 59-71$.

Rios, R. R. (2000). Prostitutas, michês e travestis: uma análise crítica do discurso jurídico sobre a prostituição e de suas consequências práticas. In A. I. Fábregaz- Martinez \& M. R. Benedetti (Orgs.), Na batalha: identidade, sexualidade e poder no universo da prostituição (pp. 81-94). Porto Alegre: Dacasa: Palmarica.

Roberts, N. (1998). As prostituas na história. Rio de Janeiro: Rosa dos Tempos.

Rodrigues, M. T. (2003). Política e prostituição feminina em Brasília: um estudo de caso. Tese de Doutorado, Programa de Pós-graduação em Sociologia, Universidade de Brasília, Brasília, DF. Recuperado de http://fci.uib.es/ digitalAssets/178/178151_2.pdf

Rodrigues, R. M. (2010). Prostituição e construção de carreiras. Dissertação de Mestrado, Programa de Pós-graduação em Psicologia, Universidade de São Paulo, SP. Recuperado de http://www.teses.usp.br/teses/disponiveis/47/47134/tde19072010-151358/pt- br.php

Rubin. G. (1989). Reflexionando sobre el sexo: notas para una teoría radical de la sexualidad. In C. S. Vance (Comp.), Placer y peligro: explorando la sexualidad femenina (pp. 113-190). Madrid: Revolución.

Santos, L. \& Mayorga, C. (2017). Entre as fronteiras do morar e o direito de decidir: uma etnografia das famílias removidas da Vila da Paz na cidade de Belo Horizonte. Revista de Direito da Cidade, 9(1), 233-275.

Sant'Ana. R. B. (2009). A autonomia do sujeito: contribuições de G. H. Mead. Psicologia: Teoria e Pesquisa, 25(4), 467477.

Scott, J. (2001). "Experiência" (M. Silva, trad.). La Ventana, $13,42-73$
Soares, L. C. (1992). Rameiras, ilhoas, polacas... a prostituição no Rio de Janeiro do século XIX. São Paulo: Ática.

Souza, J. (2003). A construção social da subcidadania: para uma sociologia politica da modernidade periférica. Belo Horizonte: Editora UFMG.

Spivak, G. C. (2010). Pode o subalterno falar? (S. R. G. Almeida; M. P. F. Feitosa, \& A. P. Feitosa, trad.). Belo Horizonte: Editora UFMG. (Trabalho original publicado em 1988)

Taylor, C. (1997). As fontes do self: a construção da identidade moderna (A. U. Sobral \& D. A. Azevedo, trad.). São Paulo: Edições Loyola.

Taylor, C. (2007). O que é agência humana? (R. Torres \& F. Maciel, trad.). In J. Souza \& P. Mattos (Orgs.), Teoria crítica no século XXI (pp. 9-39), Coleção Crítica Contemporânea. São Paulo: Annablume. (Trabalho original publicado em 1977).

Viana, N. J. Q. (2001). Caminhos e descaminhos da prostituição viril. Caderno de Estudos Sociais, 20(2), 289-304.

Submissão em: 16/06/2016

Revisão em: 21/04/2017

Aceite em: 11/09/2017

Agência de fomento: $O$ presente trabalho foi realizado com apoio da Coordenação de Aperfeiçoamento de Pessoal de Nível Superior - Brasil [CAPES] - Código de financiamento 001 doutorado; Fundação de Amparo à Pesquisa de Minas Gerais Programa Pesquisador Mineiro (2015); Conselho Nacional de Pesquisa [CNPq] - Bolsista Produtividade (2014).

André Geraldo Ribeiro Diniz é doutorando em Psicologia Social pela UFMG (2013), professor assistente do Departamento de Psicologia, Puc Minas, mestrado em Psicologia Social pela UFMG (2013). https://orcid.org/0000-0002-3086-1026

Endereço: Núcleo de Ensino, Pesquisa e Extensão Conexões de Saberes - Universidade Federal de Minas Gerais. Av. Antônio Carlos, 6627, Fafich, sala 2005, Panpulha, Belo Horizonte, Minas Gerais, Cep 31270-901. E-mail: andredinizbh@gmail.com

Claudia Mayorga é doutora em Psicologia Social pela Universidad Complutense de Madrid. Professora credenciada no PPGPsi da UFMG, coordenadora do Núcleo de Ensino, Pesquisa e Extensão Conexões de Saberes. https://orcid.org/0000-0003-1728-0726 E-mail: claudiamayorga@ufmg.br 